\title{
Cafeicultura e desenvolvimento territorial: as cooperativas de café no sul de Minas Gerais
}

\author{
Coffee cultivation and territorial development: the coffee cooperatives in the south of Minas \\ Gerais
}

\author{
Eli Fernando Tavano Toledo \\ Professor Doutor EBTT do IFSULDEMINAS - Campus Poços de Caldas, Brasil \\ Doutor em Geografia Econômica pela Unesp de Rio Claro \\ eli.toledo@ifsuldeminas.edu.br
}

\begin{abstract}
Resumo
As cooperativas são entidades que visam, através da convergência de interesses, oferecer qualidade para a produção dos cooperados, esses agrupamentos socioeconômicos detêm vigorosos laços com os territórios que os acolhem. A cafeicultura e toda a cadeia produtiva que a envolve possui relevância histórica, econômica e geográfica para o Brasil e para o estado de Minas Gerais, o qual é o maior produtor nacional. Mais especificamente para o Sul de Minas, o café e seus aparelhos produtivos são relevantes pilares para o Desenvolvimento Local e Regional. O presente trabalho objetiva averiguar quais são as cooperativas de café presentes na mesorregião Sul e Sudoeste de Minas e compreender os múltiplos vínculos que fazem das cooperativas instrumentos tão imprescindíveis para a geografia econômica do recorte espacial pesquisado. Essa investigação faz parte do programa "Cafeicultura como projeto socioeconômico para o Desenvolvimento Regional" amparado pelo Observatório do Mundo do Trabalho do IFSULDEMINAS.
\end{abstract}

Palavras-chave: Cooperativas de Café, Sul de Minas, Desenvolvimento Local/Regional, Geografia Econômica.

\begin{abstract}
The cooperatives are entities that aim, through the convergence of interests, to offer quality for the production of the cooperative, these socioeconomic groups have strong ties with the territories that host them. The coffee industry and the entire production chain that surrounds it has historical, economic and geographical relevance for Brazil and for the state of Minas Gerais, which is the largest national producer. More specifically for the South of Minas, coffee and its productive apparatus are essential pillars for local and Regional Development. The present work purpose of finding out which coffee cooperatives are present in the South and Southwest mesoregion of Minas Gerais and to understand the multiple bonds that make the cooperative instruments so essential for the economic geography of the researched space. This research is part of the program "Coffee as a socioeconomic project for Regional Development" supported by the Observatório do Mundo do Trabalho of IFSULDEMINAS.
\end{abstract}

Keywords: Coffee Cooperatives, South of Minas, Local/Regional Development, Economic Geography. 


\section{INTRODUÇÃO}

O presente trabalho faz parte das pesquisas efetuadas no Observatório do Mundo do Trabalho do IFSULDEMINAS - campus Poços de Caldas e está enquadrado no programa a "Cafeicultura como projeto socioeconômico para o Desenvolvimento Regional”, cabe destacar que o Observatório do Mundo do Trabalho (OMT) é uma ação da Reitoria do IFSULDEMINAS. O programa "Cafeicultura como projeto socioeconômico para o Desenvolvimento Regional" tem por grande objetivo identificar como a cadeia produtiva do café pode auxiliar o avanço socioeconômico local e regional, ressaltando que essa atividade não está contida apenas no setor primário, mas sua estrutura produtiva se difunde pelos outros setores da economia.

O OMT tem por característica principal apoiar trabalhos que auxiliem o desenvolvimento regional e local dos municípios que possuem campus do IFSULDEMINAS. O presente texto almeja explicitar quais as cooperativas presentes na cadeia produtiva do café sul-mineira e como auxiliam no desenvolvimento local e regional da região.

O Sul de Minas Gerais é a região que mais produz café no Brasil (tabela 1) e o IFSULDEMINAS, com seus campi, está diretamente e indiretamente entrelaçado com a atividade cafeeira em sua história e atividades presentes. Isso fica claro com os campi de Muzambinho, Inconfidentes, Carmo de Minas e Machado, somando-se a eles, mesmo não possuindo cursos atados ao café, os outros campi do IFSULDEMINAS estão localizados em municípios e microrregiões que possuem de modo significativo a atividade cafeicultora.

O café possui mais de dois séculos de história e tradição no Brasil. Há mais de 100 anos o Brasil é o maior produtor mundial e será muito difícil perder essa liderança, pois o país produz mais de um terço da capacidade mundial (Tabela 1). Sendo assim, é inegável o impacto da cafeicultura na Geografia Econômica de qualquer grande espaço cafeicultor.

Quando se retrata a cadeia produtiva do café as estruturas presentes no território são as mais diversas, entre as mais evidentes estão: as áreas produtivas, os armazéns privados e públicos, indústrias privadas de beneficiamento, as cooperativas, agências de suporte técnico (públicas e associativas), aglomeração comercial, aglomeração financeira, instituições educacionais e científicas, o corpo de mão de obra fixo, poder político, associações e toda a aglomeração de comércio e serviços. O Observatório do Mundo do Trabalho acredita que a ilustração desses elementos do espaço geográfico econômico, aqui representado pela cafeicultura, pode contribuir para as lideranças (públicas e privadas) dos pequenos e médios municípios do Sul de Minas traçar políticas de prosperidade socioeconômica mais eficazes, com participação dos atores locais e com menor desperdício do orçamento público. 
Ressaltamos que as infraestruturas (fixos) que apoiam a atividade cafeicultora também auxiliam o desenvolvimento local e regional, entre as infraestruturas de suporte pode-se indicar os meios de transportes, energia elétrica, saneamento e segurança. Cabe destacar que o Sul de Minas possui uma rede urbana composta de pequenas e médias cidades, com um quadro majoritário de pequenos municípios, assim a agropecuária é de suma importância para os aspectos socioeconômicos dos pequenos e médios municípios e, compondo a atividade agrária, a cafeicultura tem importância fundamental e explicitamente está capilarizada por essa rede de pequenos e médios municípios.

\section{PROCEDIMENTOS METODOLÓGICOS}

Para a construção do texto utilizou-se múltiplas metodologias para tomar contato e levantar as informações das cooperativas localizadas no recorte espacial aqui proposto, dentre as ferramentas optou-se pela entrevista-profunda por telefone e pesquisa nos sites das cooperativas e notícias veiculadas na internet. A revisão bibliográfica foi de enorme serventia em todo o processo, pois o conteúdo sobre as cooperativas de café no sul de minas é esparso e fragmentado. Assim, o esclarecimento (forma, conteúdo e processo) do que é cooperativa induziu a revisão de documentos dos mais diversos possíveis, tais como: livros, artigos, revistas, jornais e sites. A materialização dos resultados coletados se efetivou na redação final do trabalho.

\section{CARACTERIZAÇÃo dA ÁREA DE ESTUdo}

A área de estudo é a mesorregião Sul e Sudoeste de Minas, proposta pelo IBGE, o espaço possui 146 municípios e está dividido em 10 microrregiões, lideradas por Passos; São Sebastião do Paraíso; Alfenas; Varginha; Poços de Caldas; Pouso Alegre; Santa Rita do Sapucaí; São Lourenço; Andrelândia e Itajubá. Em 2017, de acordo com o IBGE, as maiores cidades eram Poços de Caldas com 166.085 habitantes, Pouso Alegre com 147.037; Varginha com 134.364; Passos apresentando 114.458, Lavras com 102.124 e Itajubá chegando em 2017 com 97.000 pessoas (IBGE, 2017). Como dito anteriormente, esse espaço geográfico é composto por pequenos municípios majoritariamente e os mesmos são fortemente influenciados pela atividade agraria-pastoril, os municípios de Pouso Alegre, Poços de Caldas, Varginha, Três Corações, Itajubá e Extrema possuem parques industriais representativos para a região em tela.

\section{REFERENCIAL TEÓRICO}

O tema vai ao encontro de um cabedal teórico desenvolvido pela Geografia e Economia, mais especificamente, pela Geografia Econômica, pois o desenvolvimento regional tem amplo histórico de estudo nessa ciência. Utilizando de autores como Georges Benko (1996); Michel Storper 
(1990, 1994); Allen Scott (1998); Antonio Vázquez Barquero (2002); Milton Santos e Maria Laura Silveira (2001); David Harvey (2003); Clélio Campolina Diniz (2005) podemos compreender as mudanças na configuração produtiva do espaço mundial, regional e local, deste modo montar um quadro teórico para investigar assuntos mais específicos da região proposta. Para amparar as experiências associativas e de organização dos atores regionais a pesquisa partiu dos fundamentos escritos por Elson Pires (2006, 2008 e 2011), Cassiolato, Albagli e Lastres (1999), Jimmy McIntyre (2002), em que esses autores recolhem experiências locais de enfrentamento de uma nova realidade global. Os textos "Cooperativas Agrícolas e Capitalismo no Brasil” de Maria Teresa Leme Fleury; "Movimento Cooperativista e a Cafeicultura", do Instituto Brasileiro do Café (IBC, 1965); "Formação das Cooperativas de Café no Brasil: Uma Análise Econômica e Institucional” de Juliana Vilela de SOUZA e Sigismundo Bialoskorski Neto e os trabalhos sobre a cadeia produtiva do café e sua regulamentação de Maria Sylvia Saes auxiliam a compreender o processo de formação das cooperativas de café no Brasil. Por fim, para o debate sobre cooperativismo e desenvolvimento regional o presente artigo baseia-se no texto Associativismo/cooperativismo e desenvolvimento local/regional de Waculicz, G.; Righ,I. e Cazarolii, B.

\section{RESULTADOS E DISCUSSÕES}

O desenvolvimento da economia é um dos principais componentes da política de Estado, essa entidade detém o poder de regulamentar e regular o ambiente socioeconômico. A diligência do Estado, no decorrer do processo histórico-geográfico, perpassou pela centralidade do governante (Mercantilismo), pela força da iniciativa privada, empresas e conglomerados (Liberalismo), pela simbiose entre o público e o privado (governos corporativistas), através de planejamentos de cunho estatista seja por governos de esquerda e direita (Keynesianismo) e mais recentemente pela transferência dessa responsabilidade para os Locais. Após os anos 1990, a maioria dos Estados abandonou projetos nacionais de desenvolvimento para delegarem essa incumbência às regiões e mais especificamente aos municípios. As teorias da Geografia Econômica, Administração e Economia acompanharam esse processo, pois a valorização do espaço local e regional iluminou e incentivou novos estudos em que a tessitura dos atores que compõem o espaço geográfico são conclamados a participar, organizar, coordenar, produzir, dado que a competição não se limita a escala local e regional, nesse novo momento as verticalidades econômicas ligam o Local ao Global. (BENKO, 1996); (STORPER,1990, 1994); (SCOTT, 1998).O aparecimento e a consolidação desse novo cenário proporcionou o investimento socioeconômico e intelectual em atitudes e aparelhos territoriais que, possivelmente, podem responder a esses desafios, dentre eles encontramos: os arranjos produtivos locais, consórcio de municípios, distritos industriais, clusters, câmaras de comércio e as 
cooperativas. Esses aparelhos e ações socioeconômicas objetivam aumentar a produtividade e perpetuar os elementos produtivos e sociais nos territórios (DINIZ:LEMOS, 2005). O ambiente econômico não pode se abster de nenhum ator para o fortalecimento do local, deste modo as cooperativas oferecem uma série de serviços e amparos econômicos e suporte técnico para o desenvolvimento local e regional (BARQUERO, 2002). De acordo com a Organização Brasileira de Cooperativas (OBC) e o Sebrae uma cooperativa podem ser definida como:

Cooperativa é uma organização constituída por membros de determinado grupo econômico ou social que objetiva desempenhar, em benefício comum, determinada atividade. As premissas do cooperativismo são: Identidade de propósitos e interesses; Ação conjunta, voluntária e objetiva para coordenação de contribuição e serviços; Obtenção de resultado útil e comum a todos. (SEBRAE, 2019)

As cooperativas são organizações autônomas, de ajuda mútua, controladas por seus membros, e nada deve mudar isso. Se uma cooperativa firmar acordos com outras organizações, públicas ou privadas, deve fazer em condições de assegurar o controle democrático pelos membros e a sua autonomia. (OBC, 2019)

Tabela 1 - Série Histórica de Produção - Safras 2001 - 2019 - Em mil sacas beneficiadas.

\begin{tabular}{cccc}
\hline Escala & Brasil & MG & Sul e Centro Oeste de Minas \\
\hline 2001 & 31.300 & 14.690 & 7.600 \\
2002 & 48.480 & 25.140 & 1.633 \\
2003 & 28.820 & 12.050 & 5.360 \\
2004 & 39.272 & 18.777 & 9.350 \\
2005 & 32.944 & 15.219 & 6.750 \\
2006 & 42.512 & 21.987 & 11.633 \\
2007 & 36.071 & 16.473 & 7.266 \\
2008 & 45.992 & 23.581 & 12.118 \\
2009 & 39.469 & 19.880 & 9.750 \\
2010 & 48.094 & 25.155 & 12.616 \\
2011 & 43.484 & 22.181 & 10.442 \\
2012 & 50.826 & 26.944 & 13.792 \\
2013 & 49.341 & 27.660 & 13.355 \\
2014 & 45.341 & 22.644 & 10.803 \\
2015 & 43.235 & 22.302 & 10.803 \\
2016 & 51.369 & 30.724 & 16.627 \\
2017 & 44.970 & 24.445 & 13.684 \\
2018 & 61.657 & 33.360 & 17.896 \\
$2019 *$ & 50.481 & 26.415 & 14.486 \\
\hline
\end{tabular}

Fonte: Companhia Nacional de Abastecimento - CONAB - Organizado pelo autor - 2019.

No mundo esse sistema de convergência produtiva teve início em 1844, na cidade de Rochdale-Manchester, na Inglaterra. Devido a carestia de insumos básicos para sobreviver na comunidade, 28 trabalhadores (27 homens e uma mulher) montaram um armazém que tinha por objetivo reduzir os custos de compra e repasse e se uniram para montar a primeira cooperativa que se tem notícia. Em nosso país a iniciativa foi em 1889, em Minas Gerais, com a criação da Cooperativa Econômica dos Funcionários Públicos de Ouro Preto com a intenção de facilitar a obtenção de produtos agropecuários. (OBC, 2019) 
No Brasil as cooperativas possuem, amparadas por legislação, uma estrutura definida em $\mathbf{1}^{\mathbf{0}}$ grau - Singular (Uma cooperativa para pessoas); $2^{\mathbf{0}}$ grau - Central ou Federação (cooperativa para cooperativas) e $\mathbf{3}^{\mathbf{o}}$ grau - Confederação (cooperativa para federações), toda essa organização é amparada pela Lei 5.764/1971, conhecida por "Lei Geral das Cooperativas".

Para um produtor rural as cooperativas são de enorme relevância, pois as mesmas conseguem reduzir custos, oferecer apoio técnico, fortalecer as demandas socioeconômicas e políticas dos fazendeiros, além de suporte financeiro para criar estabilidade na safra e entressafra, deste modo, a grande função da cooperativa agropecuária especialmente é tentar criar um ambiente de estabilidade para o enfretamento da complexidade da produção agrícola (SAES,1999). Especialmente para o cafeicultor os benefícios são efetivados em melhorias botânica-edáficas para seu produto, razoáveis condições de compra dos insumos, armazenagem, beneficiamento e, possível industrialização do café, proteção contra os intermediários, burocracia e logística para exportação, publicidade e agregação de valor ao produto final, além dos benefícios com parceria nas áreas de saúde, educação e segurança dos grãos e transformação da produção recebida dos cooperados, o que agrega valor, gera maior renda e empregos. (WACULICZ, G.; RIGH,I. E CAZAROLII, B., 2000)

Atualmente o país conta com 97 cooperativas sendo que a maioria dos 287 mil produtores de café, em 1.900 municípios, integram alguma associação ou cooperativa de café. As cooperativas possuem uma ação de enorme relevância na produção do café brasileiro, na safra de 2016, cerca de 51,369 milhões de sacas de $60 \mathrm{~kg}$, esses agrupamentos foram responsáveis por $48 \%$ da produção. Nunca é demais relembrar que o café é o $5^{\circ}$ produto agrícola de exportação o que rendeu US\$ 5,472 bilhões, o Brasil produz 33\% do café mundial (Tabela 1.) (MAPA; ABIC, 2017).

A força e relevância das cooperativas de café ficaram muito explícitas no parágrafo acima, essa importância exala influência no território onde existem esses agrupamentos coletivos, portanto de algum modo geram ativos significativos para o desenvolvimento local e regional, entende-se as expressões “Desenvolvimento Local”, como assevera Barquero (2002):

O desenvolvimento econômico local pode ser definido como um processo de crescimento e mudança estrutural que ocorre em razão da transferência de recursos das atividades tradicionais para as modernas, bem como pelo aproveitamento das economias externas e pela introdução de inovações, determinando a elevação do bem-estar da população de uma cidade ou região. Quando a comunidade local é capaz de utilizar o potencial de desenvolvimento e liderar o processo de mudança estrutural, pode-se falar de desenvolvimento local endógeno ou, simplesmente, de desenvolvimento endógeno. (BARQUERO, P.57, 2002)

Como definição de Desenvolvimento Regional nos espelhamos na definição de PIRES et al., (2011), os quais sustentam:

De forma geral, o desenvolvimento regional consiste em um processo de mudança estrutural localizado em nível subnacional, visualizando um progresso da própria região, da comunidade e da sociedade que nela vive. Mas, na maior parte das definições, trata-se de um 
tipo de desenvolvimento imposto por meio de política de planejamento regional. No entanto, os processos que levariam ao desenvolvimento de uma região a longo prazo seriam: I - A participação relativa da região na alocação de recursos inter-regionais, controlada geralmente pelo Estado em âmbito nacional; II - Magnitude do impacto que o quadro global da política econômica tem sobre a região, aumento do ritmo de alocação de recursos ou estagnação devido a uma força de fora da região; III - Capacidade de organização social da região para transformar os impulsos do crescimento em estados de desenvolvimento. Trata-se, nesse caso, de processo endógeno à região, associado a questões como decisão da região, o aumento da capacidade regional para reter e reinvestir o excedente econômico gerado pelo investimento em melhoramento social e preservação do meio ambiente. (PIRES et al., p.65$66,2011)$

Aproximando essas definições com a importância das cooperativas possui-se uma sintonia de ações que agregam elementos com enorme potencial de envolvimento de muitos atores para a prosperidade socioeconômica territorial contemplando múltiplos interesses em um só agrupamento.

Por definição, a cooperativa é um instrumento ideal de desenvolvimento endógeno. Pois ela é centrada na pessoa em vez do capital, por seu princípio de um membro, um voto. Ela favorece, assim, a democracia direta valorizando os interesses e as necessidades locais. $\mathrm{Na}$ teoria, a cooperativa é igualmente apresentada como um bem inalienável da comunidade, graças ao princípio de não partilhar a reserva, princípio este que coloca a cooperativa ao abrigo das tomadas de controle agressivo por interesses exteriores. Fórmula cooperativa favorece então o enraizamento a longo prazo. (WACULICZ, et al., 2000)

O dever de não partilhar a reserva está calcado dentro do princípio do cooperativismo da "Participação econômica do sócio", nesse princípio os associados devem contribuir de maneira equitativa e controlar democraticamente os recursos da cooperativa. Uma parte desse recurso é, geralmente, de posse comum dos cooperados. Os associados, na maioria das vezes, recebem benefícios limitados pelo capital existente, quando houver. Como condição de associação, esse capital tem por finalidade desenvolver a cooperativa, possibilitando a formação de reservas, onde ao menos parte delas seja indivisível; outra parte beneficiar os associados na proporção de suas transações com a cooperativa e, por fim, sustentar outras atividades aprovadas pela sociedade. (SEBRAE ; OBC, 2019)

A força do movimento cooperativista alinhada com o desenvolvimento local/regional e endógeno está na construção de tipo "bottom-up”, ou seja de baixo para cima. É notável lembrar, que ao se falar em desenvolvimento endógeno está se falando de uma ação fortalecedora do arranjo entre os membros que almejam prosperidade local e regional, portanto uma atitude que remete a obtenção de maior equalização, sintonia e retenção dos recursos financeiros e qualitativos no local. No processo de desenvolvimento endógeno as decisões construídas de baixo para cima (bottom-up) alicerçam e oferecem maior amálgama nas relações socioeconômicas, políticas e tecnológicas dos entes territoriais.

A criação das cooperativas de café no Brasil foi em parte um anseio das comunidades locais, mas também sofreu influência de políticas vindas de cima para baixo (Top-down), particularmente 
através das periódicas regulamentações advindas das políticas de café dos governos e órgãos regulatórios, além da interferência, sempre presente dos preços das commodities no mercado internacional. Souza e Bialoskorski-Neto (2004) enfatiza que existem 6 períodos de significativo avanço e retrocesso na formação de cooperativas de café no Brasil, são eles:

(1) período de crescimento e crise que se inicia durante a Primeira República e termina em meados dos anos quarenta após um longo período de crise do setor e que é caracterizado pelo predomínio dos grandes cafeicultores principalmente no estado de São Paulo; (2) período de reestruturação que se inicia por volta de 1945, com o aumento da produção e vai até 1957; (3) período de intervenção governamental em que o IBC passa a incentivar a formação de cooperativas de café de 1958 até final dos anos sessenta; (4) o período de renovação dos cafezais que foi de 1962 até meados da década de setenta, quando grande parte do parque cafeeiro foi erradicado e posteriormente replantado. O final dos anos setenta e a década de oitenta são definidos como período de (5) expansão da fronteira agrícola, pois nessa década aumentou consideravelmente a produção de café em regiões como Rondônia, Bahia e Sul de Minas Gerais. O (6) período de desregulamentação tem início em 1990 com a extinção do IBC e termina por volta de 1996 quando a cafeicultura apresenta os primeiros sinais de recuperação após um longo período de preços baixos e endividamento.

O Sul de Minas foi a região que criou a primeira cooperativa de café do Brasil, a Cooxupé, no município de Guaxupé, ela foi criada em 1932 com atividades exclusivamente financeiras para os cafeicultores, tornando-se cooperativa agrícola em 1957 (Tabela 2). Dentre as fases destacadas pelos autores, o momento 3, período de intervenção governamental, tendo como protagonista o Instituto Brasileiro do Café (IBC) nas décadas de 1950 e 60, foi o estágio de maior criação de cooperativas de café pelo país. O IBC (1952 - 1989) teve grande participação na criação e apoio das novas cooperativas, assim, foi nítida a política vinda a partir do governo federal para as localidades cafeicultoras, Souza e Bialoskorski-Neto (2004) informam:

Percebendo as vantagens do cooperativismo para a situação da cafeicultura no final dos anos cinqüenta, o IBC - Instituto Brasileiro do Café - passou a implementar uma série de incentivos à formação de novas cooperativas como linhas de crédito e concessão de facilidades à exportação. Por outro lado, essas novas associações proporcionaram benefícios aos produtores como: a redução nos custos de processamento do café, antes realizado pelos maquinistas; maiores facilidades de financiamento junto ao Banco do Brasil; redução dos custos de comercialização por meio da venda direta de café ao IBC ou de exportações realizadas diretamente pelas cooperativas e aumento da renda do produtor em função da melhor qualidade do café, que passou a ser processado pelas próprias cooperativas. (SOUZA E BIALOSKORSKI-NETO, 2004)

Esse momento de maior origem das cooperativas de café no Brasil é verificado concomitantemente no Sul de Minas, pois das 20 cooperativas pesquisadas no presente estudo 13 foram criadas nas décadas de 1950 e 60 (Tabela 2), comprovando a situação que ocorreu por todas as áreas produtivas do Brasil. Em trabalho escrito pelo IBC em 1965, já se apontava que os intermediários reduziram seu poder de barganha enquanto os cooperados, no setor primário, foram agraciados com uma parcela maior de rendimento, sabendo-se que esta situação foi um duro golpe para o intermediários, pois os mesmos monopolizavam o comércio do café antes dessa intervenção 
na política cafeeira. O documento do IBC (1965) relata que a partir de 1958 até 1965 foram criadas 95 cooperativas em um total de 116 em funcionamento no ano de 1965.

Esses fatores, aliados à política instituída pelo IBC, de incentivar a fundação de novas cooperativas, a partir de 1958, proporcionaram o grande desenvolvimento obtido a seguir pelo movimento. Desse modo, das 116 entidades registradas (...), e em funcionamento no segundo trimestre desse ano [1965], 95 foram implantadas a partir de 1958” (IBC 1965).

As décadas de 1950 e 1960 apresentaram uma certa recuperação e estabilidade nos preços da saca de café, entretanto a partir de 1968 ocorre uma drástica queda na cotação, mas as cooperativas já apresentavam inúmeras vantagens aos cooperados, pois mesmo com retornos mais baixos os impactos negativos eram amortecidos pelos serviços prestados pelas cooperativas coadunados com o apoio público, “As cooperativas aparecem então como uma forma de minimizar os riscos característicos desse mercado, porém a grande maioria dessas organizações fundadas durante o período de intervenção governamental recebeu incentivos do IBC e linhas de crédito do Banco do Brasil para se formarem.” (SOUZA ; BIALOSKORSKI-NETO, 2004)

As décadas posteriores apresentaram mudanças na configuração geográfica na produção do café, já que o Sul de Minas, O Espírito Santo, Rondônia e Bahia passaram a liderar a produção cafeeira do país, somando-se a esse fato ocorre uma significativa redução da participação pública na regulação da atividade cafeeira, como maior destaque o fim do IBC em 1989.

O Sul de Minas Gerais na dinâmica geográfica da cafeicultura brasileira foi influenciada pela expansão da produção vinda da zona da mata mineira e da mogiana paulista a partir do século XIX, posteriormente no século XX a atividade passou de coadjuvante no cenário nacional para protagonista, já que a partir de 1969, com a intenção de administrar a oferta e a demanda do café, o poder federal iniciou o Plano de Renovação e Revigoramento dos Cafezais (PRRC). O IBC teve enorme participação no PRRC, o instituto estava presente nas principais áreas produtoras de café, e não foi diferente para o Sul de Minas, no ano de 1972, Varginha foi o primeiro município sul-mineiro a iniciar o replantio e renovação dos cafezais.

Essa intervenção do poder público adicionado com geadas em São Paulo e, especificamente no Paraná (1975), incentivaram áreas mais propícias naturalmente para recepção dos cafezais, em vista disso, o Sul de Minas robusteceu sua tendência histórico-natural na produção nacional. Mesmo com uma maior participação no parque cafeeiro nacional, o Sul de Minas diminuiu o ritmo de criação de cooperativas nos anos 1980 e 90, pois as antigas cooperativas ganharam maior força e representação perante os cafeicultores, nessas décadas foram criadas três cooperativas (Tabela 2). Por fim, nos anos 2000 foram formadas mais três cooperativas, o grande impulso para o surgimento desses agrupamentos estava atrelado ao apelo a uma cafeicultura orgânica e de café de alta qualidade, destinado à exportação. 
Como a presentada na tabela 1 , Minas Gerais produz mais da metade do café brasileiro, o estado possui 54 cooperativas de café, sendo que esses aglomerados de cooperação reúnem 81.397 associados e 7.162 empregados. As cooperativas produziram 11,2 milhões de sacas em 2017, dados publicados pelo Sistema da Organização das Cooperativas do Estado de Minas Gerais - Ocemg. O volume de recursos com a vendo do café foi de $\mathrm{R} \$ 6,04$ bilhões, isto significa um terço de todas as cooperativas agropecuárias de Minas Geras. O valor de patrimônio líquido movimentado pelas agropecuárias de café em 2017 chegou a R\$ 1,7 bilhão. (REVISTA CAFEICULTURA, 2019)

A mesorregião do Sul e Sudoeste de Minas é a região do país que possui o maior número de cooperativas, esse fato é concretizado pela grande presença de pequenas propriedades no espaço agrário da região, assim as cooperativas tiveram um sólido ambiente para se consolidarem durante décadas de forte e baixa intervenção pública.

Como exemplo de intensa participação das cooperativas no espaço sul mineiro, na região encontra-se a Cooxupé que é a maior e mais poderosa cooperativa de café do mundo. Atualmente, a cooperativa "possui mais de 14 mil cooperados - 95\% deles pequenos produtores que vivem da agricultura familiar," a cooperativa recebe grãos de 200 municípios no sul de Minas, Cerrado Mineiro e Vale do Rio Pardo (no estado de São Paulo). (COOXUPÉ, 2019). A cooperativa está presente desde o apoio técnico-financeiro, armazenagem, exportação, beneficiamento e industrialização do café. A influência da COOXUPÉ, no sul de minas, faz com que ela rivalize com as outras cooperativas na região, induzindo os produtores a participarem em mais de uma cooperativa.

Seguindo o mesmo modelo da Cooxupé de expansão, beneficiamento do café e diversidade nos serviços prestados aos cooperados, três cooperativas possuem relevante atuação na região, pois esses grupos possuem mais de 5 mil cooperados, além de atuarem em muitos municípios do sul de Minas, elas são a Capebe com sede na cidade de Boa Esperança (7000 cooperados), a Minasul em Varginha (6000 cooperados) e no município de Três Pontas a Cocatrel - (5000 cooperados).

Da mesma forma, a pesquisa radiografou três cooperativas apresentando um quadro acima de 2000 cooperados e de histórica participação na cafeicultura local e regional, são elas as cooperativas Coopama (Machado), Coopervass (São Gonçalo do Sapucaí) e a Coopercam (Campos Gerais), elas exercem estreita relação produtiva com os municípios sede e entorno próximo, fato considerável é que essas cidades possuem uma demografia reduzida, consequentemente as cooperativas aumentam o peso e a importância política, cultural e econômica entre as lideranças e população dessas localidades.

A partir dos anos 2000 foi grande o movimento de agregação de valores ambientais e socioculturais na cafeicultura, na região existem duas cooperativas que se especializaram na produção orgânica. Essa anexação de valores faz com que os grãos recebam precificações mais elevadas e espaço no mercado externo, sedimentando esse programa de especialização encontram-se a 
COOPERVITAE no município de Nova Resende (120 cooperados) e a Coopfam na cidade de Poço Fundo (500 cooperados). A Coopfam apresenta um excelente trabalho com as mulheres agricultoras a cooperativa criou o MOBI - Mulheres Organizadas em Busca de Independência, esse movimento ofereceu apoio técnico, financeiro e educativo para que as agricultoras pudessem aprimorar o ambiente de trabalho em suas lavouras e elevar a renda da família, fruto desse trabalho é o "Café Feminino Sustentável" exportado e vendido em várias lojas da região, de acordo com a cooperativa o Café Feminino foi o café escolhido para ser servido na Copa do Mundo no Brasil em 2014.

No Sul de Minas de Minas Gerais toda a produção é de café arábica, com suas diversas variações, esse cafés são propícios para se obterem altíssima qualidade (aroma e sabor), a região por sua configuração geomorfológica, planalto elevado e clima ameno está a cada safra produzindo maior quantidade de cafés de alta qualidade, conhecidos como gourmet e especial. As cooperativas possuem grande responsabilidade nesse processo, pois oferecem recursos técnicos e financeiros para o produtor realizar esse investimento que não pode ser feito em curto prazo. As grandes cooperativas possuem linhas de café de alta qualidade industrializado, mas as pequenas cooperativas conseguem resultados expressivos com seus cooperados. As cooperativas de Varginha (Coopercafem) e de Carmo de Minas (COCARIVE) são especializadas em cafés de alta qualidade. De acordo com o site oficial, a COCARIVE, com seus 661 cooperados, fornece serviços com "alto nível de especialização na avaliação e degustação dos cafés diferenciados." Pelo excelente padrão conquistado consolidou reconhecidamente como uma área dos melhores cafés do Brasil fruto desse procedimento a cooperativa exporta para os EUA, Japão, Austrália, Coréia, Bélgica e Itália.

Tabela 2 - Cooperativas de café presentes no Sul de Minas.

\begin{tabular}{|c|c|c|c|c|c|c|}
\hline & Cooperativa & Cidade & $\begin{array}{c}\text { Ano de } \\
\text { Inauguração }\end{array}$ & Associados & Municípios alcançados & Produtos \\
\hline 1 & $\begin{array}{l}\text { Cooperativa Regional dos Cafeicultores } \\
\text { em Guaxupé Ltda (Cooxupé) }\end{array}$ & Guaxupé & 1932 e $1957^{*}$ & 14.000 & $\begin{array}{l}200 \text { municípios de sua } \\
\text { área de ação, localizada } \\
\text { nas regiões do Sul de } \\
\text { Minas, Cerrado Mineiro } \\
\text { e Vale do Rio Pardo (no } \\
\text { estado de São Paulo) } \\
\end{array}$ & $\begin{array}{l}\text { Café, } \\
\text { milho, } \\
\text { ração e } \\
\text { cafés de } \\
\text { alta } \\
\text { qualidade }\end{array}$ \\
\hline 2 & $\begin{array}{c}\text { Cooperativa Agrária de Machado Ltda } \\
\text { (Coopama) }\end{array}$ & Machado & 1944 e $1966^{*}$ & 2.300 & $\begin{array}{l}\text { Alfenas, Elói Mendes, } \\
\text { Machado, Poço Fundo } \\
\text { e Turvolândia }\end{array}$ & $\begin{array}{l}\text { Café, } \\
\text { milho, soja, } \\
\text { fertilizante, } \\
\text { leite e } \\
\text { ração }\end{array}$ \\
\hline 3 & $\begin{array}{l}\text { Cooperativa Agropecuária de Boa } \\
\text { Esperança Ltda (Capebe) }\end{array}$ & Boa Esperança & $1963^{*}$ & 7.000 & $\begin{array}{l}\text { Campo do Meio, } \\
\text { Coqueiral, Cristais, } \\
\text { Guapé, Ilicínea e } \\
\text { Nepomuceno. }\end{array}$ & $\begin{array}{c}\text { Café, } \\
\text { milho leite } \\
\text { e derivados }\end{array}$ \\
\hline 4 & $\begin{array}{l}\text { Cooperativa dos Produtores de Café } \\
\text { Especial de Boa Esperança Ltda }\end{array}$ & Boa Esperança & $2009^{*}$ & 196 & Boa Esperança & $\begin{array}{c}\text { Café } \\
\text { especial }\end{array}$ \\
\hline 5 & $\begin{array}{l}\text { Cooperativa Agropecuária do Vale do } \\
\text { Sapucaí Ltda (Coopervass) }\end{array}$ & $\begin{array}{l}\text { São Gonçalo do } \\
\text { Sapucaí }\end{array}$ & $1960 *$ & 2.600 & $\begin{array}{c}\text { São Gonçalo do } \\
\text { Sapucaí, Campanha, } \\
\text { Heliodora, Jesuânia, } \\
\text { Lambari, Monsenhor } \\
\text { Paulo, Natércia, } \\
\text { Silvianópolis, Três } \\
\text { Corações,Turvolândia }\end{array}$ & $\begin{array}{l}\text { Leite e } \\
\text { derivados, } \\
\text { café, ração }\end{array}$ \\
\hline 6 & $\begin{array}{c}\text { Cooperativa dos Cafeicultores da Zona de } \\
\text { Varginha Ltda (Minasul) }\end{array}$ & Varginha & $1958 *$ & 6.000 & $\begin{array}{l}150 \text { municípios } \\
\text { mineiros, Centro oeste } \\
\text { e Chapada de Minas. }\end{array}$ & Café \\
\hline
\end{tabular}




\begin{tabular}{|c|c|c|c|c|c|c|}
\hline 7 & $\begin{array}{c}\text { Cooperativa dos Cafeicultores de Campos } \\
\text { Gerais e Campo do Meio Ltda } \\
\text { (Coopercam) }\end{array}$ & Campos Gerais & $1980 *$ & 2.970 & $\begin{array}{l}\text { Campos Gerais, Campo } \\
\text { do Meio, distrito de } \\
\text { Córrego do Ouro e } \\
\text { cidades circunvizinhas. }\end{array}$ & $\begin{array}{l}\text { Café, leite } \\
\text { e derivados }\end{array}$ \\
\hline 8 & $\begin{array}{c}\text { Cooperativa dos Cafeicultores da Zona de } \\
\text { Três Pontas Ltda (Cocatrel) }\end{array}$ & Três Pontas & $1961 *$ & 5.000 & $\begin{array}{c}\text { Santana da Vargem, } \\
\text { Coqueiral, } \\
\text { Nepomuceno, Carmo } \\
\text { da Cachoeira, Ilicínea, } \\
\text { Córrego do Ouro, } \\
\text { Varginha e Santo } \\
\text { Antônio do Amparo e } \\
\text { mais } 90 \text { municípios. }\end{array}$ & $\begin{array}{l}\text { Café, leite } \\
\text { e derivados }\end{array}$ \\
\hline 9 & $\begin{array}{l}\text { Cooperativa dos Produtores de Café } \\
\text { Especial dos Martins (Coopercafem) }\end{array}$ & Varginha & $2011^{*}$ & 81 & $\begin{array}{c}\text { Varginha, Três } \\
\text { Corações, São Bento } \\
\text { Abade, São Thomé das } \\
\text { Letras, Cambuquira, } \\
\text { Carmo da Cachoeira e } \\
\text { São João da Mata. }\end{array}$ & $\begin{array}{l}\text { Café } \\
\text { Especial }\end{array}$ \\
\hline 10 & $\begin{array}{c}\text { Cooperativa Regional dos Cafeicultores } \\
\text { de São Sebastião do Paraíso - } \\
\text { Coopercitrus Cooperativa de Produtores } \\
\text { Rurais }\end{array}$ & $\begin{array}{l}\text { São Sebastião } \\
\text { do Paraíso }\end{array}$ & $1960-2015$ & 400 & $\begin{array}{l}\text { São Sebastião do } \\
\text { Paraíso }\end{array}$ & $\begin{array}{c}\text { Café } \\
\text { convencion } \\
\text { al }\end{array}$ \\
\hline 11 & $\begin{array}{l}\text { Cooperativa Regional dos Cafeicultores } \\
\text { de Poços de Caldas - CaféPoços }\end{array}$ & Poços de Caldas & $1959 *$ & 584 & $\begin{array}{c}\text { Poços de Caldas, } \\
\text { Guaranésia, Cabo } \\
\text { Verde, Andradas, } \\
\text { Botelhos, Machado, } \\
\text { Campestre, no estado } \\
\text { de São Paulo: Águas da } \\
\text { Prata, Caconde, São } \\
\text { Sebastião da Grama, } \\
\text { Divinolândia }\end{array}$ & $\begin{array}{c}\text { Café } \\
\text { Convencio } \\
\text { nal e } \\
\text { Especial }\end{array}$ \\
\hline 12 & $\begin{array}{c}\text { Cooperativa Mista Agropecuária de } \\
\text { Paraguaçu }\end{array}$ & Paraguaçu & $1957 *$ & 550 & Paraguaçu & Café \\
\hline 13 & $\begin{array}{l}\text { Cooperativa Regional Agropecuária de } \\
\text { Santa Rita do Sapucaí - CooperRita }\end{array}$ & $\begin{array}{l}\text { Santa Rita do } \\
\text { Sapucaí }\end{array}$ & $1957 *$ & 1.000 & $\begin{array}{l}\text { Santa Rita do Sapucaí, } \\
\text { Pouso Alegre, Itajubá, } \\
\text { Pedralva, Carmo de } \\
\text { Minas, Conceição do } \\
\text { Rio Verde, Careaçu, } \\
\text { Cachoeira de Minas. }\end{array}$ & $\begin{array}{l}\text { leite, café, } \\
\text { indústria de } \\
\text { lácteos } \\
\text { (doce de } \\
\text { leite, } \\
\text { requeijão, } \\
\text { queijo, } \\
\text { iogurte e } \\
\text { manteiga } \\
\end{array}$ \\
\hline 14 & $\begin{array}{l}\text { Cooperativa Regional dos Cafeicultores } \\
\text { do Vale do Rio Verde Ltda - COCARIVE }\end{array}$ & Carmo de Minas & $1961 *$ & 661 & $\begin{array}{l}\text { Carmo de Minas e } \\
\text { Região }\end{array}$ & $\begin{array}{c}\text { Café } \\
\text { Especial e } \\
\text { Convencio } \\
\text { nal } \\
\end{array}$ \\
\hline 15 & $\begin{array}{c}\text { Cooperativa Agropecuária de Ilicínea } \\
\text { Ltda }\end{array}$ & Ilicínea & 2002 & 450 & Ilicínea & $\begin{array}{c}\text { Café } \\
\text { convencion } \\
\text { al } \\
\end{array}$ \\
\hline 16 & Cooperativa Agropecuária de Jacutinga & Jacutinga & $1962 *$ & 1.500 & $\begin{array}{l}\text { Jacutinga, Borda da } \\
\text { Mata, Inconfidentes e } \\
\text { Ouro Fino. } \\
\end{array}$ & $\begin{array}{c}\text { Café } \\
\text { Convencio } \\
\text { nal } \\
\end{array}$ \\
\hline 17 & Cooperativa Alto Rio Grande - CAARG & Lavras & $1953 *$ & 1.300 & Lavras e Região & $\begin{array}{l}\text { Milho, } \\
\text { Café, } \\
\text { Laticínios e } \\
\text { ração }\end{array}$ \\
\hline 18 & $\begin{array}{l}\text { Cooperativa dos Agricultores Familiares } \\
\text { de Poço Fundo e Região - Coopfam }\end{array}$ & Poço Fundo & $1991-2003 *$ & 500 & Poço Fundo e Machado & $\begin{array}{c}\text { Café } \\
\text { Orgânico } \\
\end{array}$ \\
\hline 19 & $\begin{array}{c}\text { Cooperativa Agropecuária Regional de } \\
\text { Andradas (CARA) - Cooperativa de } \\
\text { Produtores Rurais de Bebedouro - SP } \\
\text { (Coopercitrus). }\end{array}$ & Andradas & $1990-2016$ & 1.000 & Andradas & $\begin{array}{c}\text { Café } \\
\text { Convencio } \\
\text { nal }\end{array}$ \\
\hline 20 & $\begin{array}{c}\text { Cooperativa Agropecuária dos Produtores } \\
\text { Orgânicos de Nova Resende e Região } \\
\text { Ltda (COOPERVITAE) }\end{array}$ & Nova Resende & $2011^{*}$ & 120 & Nova Resende e região & $\begin{array}{c}\text { Café } \\
\text { Gourmet e } \\
\text { Orgânico }\end{array}$ \\
\hline
\end{tabular}

Fonte: Pesquisa própria, (Toledo, 2019) *Cooperativas que possuem site. 
Não existem apenas casos de resiliência e sucesso com as cooperativas do Sul de Minas, algumas passaram por problemas, incorporações e reestruturações. As causas mais relatas para esses insucessos foram a má administração, atos ilícitos, preços voláteis, operações no mercado futuro equivocadas e redução da participação de cooperados. Como exemplo, duas cooperativas passaram por incorporação e reestruturação, forma elas: a Cooperativa Regional dos Cafeicultores de São Sebastião do Paraíso e a Cooperativa Agropecuária Regional de Andradas, ambas foram incorporadas pela Coopercitrus com sede em Bebedouro - SP. A cooperativa de São Sebastião do Paraíso chegou a ter 5,2 mil cooperados, mas no ano de 2015 e com dívida total de $\mathrm{R} \$ 230$ milhões foi incorporada pela Coopercitrus que teve de assumir o passivo e gerenciar a cooperativa.

Entretanto, em Muzambinho, município com extenso e importante parque cafeeiro, foi palco do fechamento da Cooperativa Agropecuária de Muzambinho (Cooman), esse agrupamento foi fundado em 1970, mas por atos ilícitos dos controladores faliu em 2004, somente em 2012, seus bens começaram a ser leiloados para o pagamento de credores e associados, a cooperativa chegou a ter 6 mil cooperados. (EPTV Sul de Minas, 2019)

\section{CONCLUSÕES}

O presente artigo buscou levantar as cooperativas ligadas a cafeicultura na mesorregião Sul Sudoeste de Minas, lembrando que o trabalho faz parte do programa "Cafeicultura como projeto socioeconômico para o Desenvolvimento Regional” promovido pelo Observatório do Mundo do Trabalho do IFSULDEMINAS. Esse primeiro contato quantitativo, entrevistas e de rastreabilidade das cooperativas existentes demonstrou que a região em tela possui o maior número de cooperativas de café do país, retratando a condição de primeira colocação nacional na produção de café que o Sul e Sudoeste de Minas detêm.

Através da metodologia de revisão bibliográfica ficou evidente a importância da cooperativa para atividade de cafeicultura, pois a produção organizada por essa entidade socioeconômica propicia aos cooperados inúmeras vantagens, tais como: orientação ao produtor nas questões comerciais, transferência rápida e flexível de tecnologias, operações sofisticadas para o comércio do café, ações que qualificam o produtor e o produto, melhor remuneração e controle de custos de produção para resistir aos períodos de baixa e aproveitar os momentos de alta. As missões expressadas pela Cooperativa Regional dos Cafeicultores do Vale do Rio Verde (COCARIVE) e pela Cooperativa dos Agricultores Familiares de Poço Fundo e Região (Coopfam) traduzem a os objetivos buscados por essa ampla pesquisa:

Promover o desenvolvimento regional e de seus cooperados através da comercialização de seus produtos nos mercados interno e externo, focando especialmente os diferenciais da 
qualidade dos cafés da região, além de fornecer insumos e bens de consumo em condições favoráveis e, ainda, assistência técnica especializada. (COCARIVE, 2019)

Uma cadeia consciente de ações que transforma ideias, mentalidades, pessoas, vidas, comunidades, relações de produção e consumo para garantir sustentabilidade, qualidade de vida e rendimentos justos para todos. (Coopfam, 2019)

A pesquisa nos sites das cooperativas e nas entrevistas diretas pôde-se reunir as seguintes informações gerais:

- Majoritariamente, as cooperativas servem e são compostas por pequenos produtores e agricultura familiar (policultura);

- A cadeia produtiva de laticínios possui grande participação nas cooperativas;

- Muitos produtores são cooperados em duas cooperativas;

- Policultura nas pequenas e médias fazendas;

- Cooperativas com serviços de Café, Grãos e Leite;

- Busca de certificações: FLO/FairTrade - UTZ, 4C, Conab, BSCA, certificação orgânica BCS-OKO Garantie, habilitação para negociar no mercado futuro e certificação de armazenagem;

- Maior parte das cooperativas possui sites com bom acesso a comunicação;

- Maioria possui lojas de grande importância na cidade e fazem comércio eletrônico pelo site.

Esse grande número constatado de cooperativas, no Sul e Sudoeste de Minas, pode ser explicado pelo constante e histórico cultivo do café na mesorregião, desse modo, as várias forças políticas e econômicas vindas de cima (top-down) ou iniciadas pelos atores locais (bottom-up) foram conjugadas e ou se fizeram presentes de maneira mais e menos intensas no decorrer do tempo. Com esse exercício de fazer parte constante da produção cafeeira do Brasil, as cooperativas de café usufruíram e foram influenciadas pela estrutura agrária com grande quantidade de pequenos e médios produtores, participação de todas as políticas intervencionistas mais importantes da história do café no país e, após a década de 1970, a fixação da cultura pelos excelentes atributos naturais para a produção de cafés de alta qualidade.

As cooperativas, de forma significativa, contribuíram e contribuem para o crescimento e desenvolvimento local/regional da área estudada, como demonstrado em um primeiro levantamento, algumas pequenas cidades orbitam e fazem parte na atuação das cooperativas. Mesmo não possuindo de maneira sistemática políticas organizadas de desenvolvimento local/regional os elementos de ação das cooperativas desde quando foram criadas evocam e coagulam os interesses dos vários atores locais e regionais, portanto a presença de uma cooperativa, de algum modo, promove a prosperidade de onde está localizada.

O presente artigo organizou e apontou os próximos passos que a pesquisa do Observatório do Mundo do Trabalho deve tomar, os quais estão baseados no entendimento do alcance socioeconômico que essas cooperativas exercem em suas redes geográficas e, a partir dessa 
percepção, compreender as razões desses territórios apresentarem importante traço de resiliência e desenvolvimento socioeconômicos coadunados a cafeicultura.

\section{REFERÊNCIAS}

ABIC. Cooperativas são responsáveis por $\mathbf{4 8 \%}$ da produção de café do país. Disponível em: http://abic.com.br/cooperativas-sao-responsaveis-por-48-da-producao-de-cafe-do-pais/. Acesso em: 20 mar. 2019.

BARQUERO, A. V. Desenvolvimento endógeno em tempos de Globalização. 1. ed. Porto Alegre: Editora UFRGS, 2002. 280p.

BENKO, G. Economia, espaço e globalização: Na aurora do século XXI. 1. ed. São Paulo: Hucitec, 1996. 266p.

BUENO, D. G. M. Institutos Federais de Educação, Ciência e Tecnologia: uma política a ser cravada na História. 1. ed. Curitiba: Editora Appris, 2015. 151p.

CAARG - Cooperativa Alto Rio Grande. Disponível em: http://www.caarg.com.br/a_caarg.html. Acesso em: 20 mar. 2019.

CAFÉPOÇOS. Cooperativa Regional dos Cafeicultores de Poços de Caldas. Disponível em: http://cafepocos.com.br/backupsite/crbst_1.html. Acesso em: 21 mar. 2019.

CAPEBE - Cooperativa Agropecuária de Boa Esperança Ltda. Disponível em: http://www.capebe.com.br/servicos.php. Acesso em: 20 mar. 2019.

CASSIOLATO, J. E; LASTRES, H. M. M. (Eds.). Globalização e Inovação Localizada: experiências e sistemas locais no MERCOSUL. 1. ed. Brasília: IBICT/MCT, 1999. 799p.

COCATREL. Cooperativa dos Cafeicultores da Zona de Três Pontas Ltda. Disponível em: https://www.portalcocatrel.com/institucional. Acesso em: 21 mar. 2019.

CCCMG. Centro do Comércio de Café do Estado de Minas Gerais Disponível em: http://cccmg.com.br/sobre/. Acesso em: 20 mar. 2019.

COCARIVE - Cooperativa Regional dos Cafeicultores do Vale do Rio Verde Ltda. Disponível em: <http://www.cocarive.com.br/certificacao.php\#centro. Acesso em: 21 mar. 2019.

COCCAMIG - Cooperativa Central de Cafeicultores e Agropecuaristas de Minas Gerais Disponível em: http://www.coccamig.com.br/cooperativas.asp. Acesso em: 20 mar. 2019.

CONAB. Companhia Nacional de Abastecimento. Série histórica das safras - Café Total (Arábica e Conilon). Disponível em: https://www.conab.gov.br/info-agro/safras/serie-historica-das-safras. Acesso em: 20 mar. 2019.

COOMAP - Cooperativa Mista Agropecuária de Paraguaçu. Disponível em: <http://coomap.com.br/pt/a-coomap/. Acesso em: 20 mar. 2019.

COOPAMA. Cooperativa Agrária de Machado Ltda. Disponível em: <https://coopama.com.br/institucional/>. Acesso em: 20 mar. 2019. 
COOPERCAM. Cooperativa dos Cafeicultores de Campos Gerais e Campo do Meio Ltda. Disponível em: < http://coopercam.com.br/site/pagina/institucional >. Acesso em: 20 mar. 2019.

COOPFAM. Cooperativa dos Agricultores Familiares de Poço Fundo e Região. Disponível em: <https://coopfam.com.br/>. Acesso em: 20 mar. 2019.

CPCEBE. Cooperativa dos Produtores de Café Especial de Boa Esperança Ltda. Disponível em: https://www.costas5588.com.br/. Acesso em: 20 mar. 2019.

COOPERCITRUS. Cooperativa de Produtores Rurais de Bebedouro - SP. Andradas e São Sebastião do Paraíso. Disponível em: <https://www.coopercitrus.com.br/?pag=unidades\&cidade=ANDRADAS $>$. Acesso em: 20 mar. 2019.

COOPERVASS. Cooperativa Agropecuária do Vale do Sapucaí Ltda. Disponível em: <https://coopervass.com.br/>. Acesso em: 20 mar. 2019.

COAPEJA. Cooperativa Agropecuária de Jacutinga. Disponível em: < http://www.coapeja.com.br/ >. Acesso em: 20 mar. 2019.

COOPERCAFEM. Cooperativa dos Produtores de Café Especial dos Martins. Disponível em: http://www.coopercafem.com.br/. Acesso em: 20 mar. 2019.

COOPERVITAE. Cooperativa Agropecuária dos Produtores Orgânicos de Nova Resende e Região Ltda. Disponível em: <https://coopervitae.com.br/quem-somos/>. Acesso em: 21 mar. 2019.

COOXUPE. Cooperativa Regional dos Cafeicultores em Guaxupé Ltda Disponível em: <https://www.cooxupe.com.br/>. Acesso em: 22 mar. 2019.

COOPERRITA. Cooperativa Regional Agropecuária de Santa Rita do Sapucaí - CooperRita. Disponível em: < http://www.cooperrita.com.br/empresa-historia >. Acesso em: 22 mar. 2019.

DINIZ, C. C.; LEMOS, M. B. Economia e Território. 1. ed. Belo Horizonte: Editora UFMG, 2005. $578 \mathrm{p}$.

EPTV - Sul de Minas. Cooparaíso já pagou $40 \%$ das dívidas desde parceria com cooperativa de SP. Disponível em: https://g1.globo.com/mg/sul-de-minas/grao-sagrado/noticia/cooparaiso-japagou-40-das-dividas-desde-parceria-com-cooperativa-de-sp.ghtml. Acesso em: 20 mar. 2019.

EPTV - Sul de Minas. Cooperativa de Andradas passará a ser controlada pela Coopercitrus. Disponível em: < http:/g1.globo.com/mg/sul-de-minas/noticia/2016/02/cooperativa-de-andradaspassara-ser-controlada-pela-coopercitrus.html >. Acesso em: 20 mar. 2019.

EPTV - Sul de Minas. Crime de ex-presidente de cooperativa falida prescreve em Muzambinho, MG. Disponivel em: < http://g1.globo.com/mg/sul-de-minas/noticia/2017/01/crime-de-expresidente-de-cooperativa-falida-prescreve-em-mg.html>. Acesso em: 20 mar. 2019.

LASTRES, H.; ALBIGLI, S. (Orgs.). Informação e Globalização na era do conhecimento. 1. ed. Rio de Janeiro: Campus, 1999. 318p.

MINASUL - Cooperativa dos Cafeicultores da Zona de Varginha. Ltda. Disponível em: https://www.minasul.com.br/pt/institucional/minasul-em-numeros. Acesso em: 20 mar. 2019. 
MCINTYRE, J.; SILVA, E. Como formar e gerir um empreendimento cooperativo - Série cooperativismo. Recife, SEBRAE, 2002

OBC - Organização das Cooperativas do Brasil. Disponível em: <https://www.ocb.org.br/>. Acesso em: 20 mar. 2019.

PIRES, E.; FUINI, L.; MANCINI, R.; PICCOLI, D. Governança Territorial: conceitos, fatos e modalidades. 1. ed. Rio Claro: Editora UNESP, 2011. 192p.

PORTER, M. E. A vantagem competitiva das Nações. 1. ed. Rio de Janeiro: Editora Campus, 1990. 920p.

REVISTA CAFEICULTURA. Cooperativas mineiras marcam presença na Semana Internacional do Café, em Belo Horizonte. 2018. Disponível em: http://revistacafeicultura.com.br/?mat=67013. Acesso em: 22 mar. 2019.

SAES, M. S. M.; NAKAZONE, D. Estudo da Competitividade de Cadeias Integradas no Brasil: Impactos das Zonas de Livre Comércio - Cadeia: Café. 1. ed. Campinas: UNICAMP-IE-NEIT, 2002. $142 \mathrm{p}$.

SAES, M. S. M. A racionalidade econômica da regulamentação no mercado brasileiro de café. 3. ed. São Paulo: Campus, 1997. 221p.

SAES, M. S. M.; FARINA, E. M. M. Q. O Agribusiness do Café no Brasil. 1. ed. São Paulo: Pensa/Milkbizz, 1999. 230p.

SEBRAE - Serviço Brasileiro de Apoio às Micro e Pequenas Empresas Disponível em: http://www.sebrae.com.br/sites/PortalSebrae/artigos/como-criar-uma-cooperativa. Acesso em: 20 mar. 2019.

SOUZA, J.; BIALOSKORSKI NETO, S. Formação das Cooperativas de Café no Brasil: Uma Análise Econômica e Institucional. $\quad$ Disponível em: http://www.sober.org.br/palestra/12/04O240.pdf>. Acesso em 20 mar. 2019.

WACHHOLZ, L.; POYER, M. G. A importância das cooperativas cafeicultoras para os pequenos agricultores na exportação de café na região Sul de Minas Gerais. Revista Gestão e Sustentabilidade Ambiental, Florianópolis, v. 2, n. 2, p. 27-44, 2013.

WAKULICZ, G.; RIGHI, I. M. M.; CAZAROLLI, B. Associativismo/cooperativismo e desenvolvimento local/regional. Revista Economia e Desenvolvimento, Santa Maria, n. 11, p. 177187, 2000.

Trabalho recebido em 30/07/2019

Trabalho aceito em 05/08/19 